\title{
Half Maximal Inhibitory Concentration Fold Change from Baseline Measurement
}

National Cancer Institute

\section{Source}

National Cancer Institute. Half Maximal Inhibitory Concentration Fold Change from

Baseline Measurement. NCI Thesaurus. Code C116250.

A fold change based on a concentration of a specific drug expected to produce $50 \%$ inhibition of the standard growth of a viral organism, or of a biological/biochemical reaction. It is a ratio calculated by the current IC50 Treatment Result divided by the IC50 Treatment Result from the baseline visit. 